\title{
Attraction to light - from how far do moths (Lepidoptera) return to weak artificial sources of light?
}

\author{
Christine TRUXA and KonRAD FIEDLER
}

Department of Animal Biodiversity, University of Vienna, Rennweg 14, Vienna, Austria; e-mail: christine.truxa@gmx.at

Key words. Lepidoptera, low power light traps, mark-release-recapture, attraction range

\begin{abstract}
Moths are frequently used as indicators of biodiversity or habitat quality. Light traps are the most effective and widely used method for gathering data on moth communities. Knowing the distance from which moths are drawn to a light trap is therefore essential for the ecological interpretation of such data. Two community-wide mark-release-recapture experiments were carried out in forest habitats in central Europe in order to investigate whether the percentage of marked moths recaptured at weak artificial light sources $(2 \times 15 \mathrm{~W}$ UV-light tubes) is dependent on the distance they were released from the light source. Altogether 2,331 moths belonging to 167 species were caught at light traps and released at distances of $2-100 \mathrm{~m}$. Of these moths 313 returned to the light trap within 5 min of release. Percentage recapture was generally low (gross rate 13.4\%) and strongly decreased with increase in the distance at which they were released. Percentage recapture was not significantly affected by ambient temperature or the sex of the moths. Only for the Geometroidea was the percentage recaptured slightly greater for the larger species. We found no significant differences between moth super-families with regard to the distance dependence of their attraction to light. Our data confirm that the radius of attraction of low powered light traps for moths is very small often even below $10 \mathrm{~m}$. Thus, moths are good indicators of habitat quality and fragmentation as they are rarely attracted from distant habitats to such light traps.
\end{abstract}

\section{INTRODUCTION}

Light traps are the most widely used and most efficient method used to survey nocturnal insects - especially moths - at population and community levels (Young, 2005). Although light traps provide an excellent method of gathering standardized and comparable data, there are many factors that influence the abundance and composition of light trap catches. It is known that moth catches are significantly influenced by the type of trap, sampling mode (manual vs. automatic), time of day, season and duration of sampling (Thomas \& Thomas, 1994; Axmacher \& Fiedler, 2004; Summerville \& Crist 2005; Beck \& Chey, 2007). Catch size and composition are also determined by the light source employed and its spectral composition (Leinonen et al., 1998; Fayle et al., 2007). In addition to the type of trap and equipment a range of abiotic factors affect the efficiency of light traps, such as temperature, rainfall, moonlight and cloud cover (Holyoak et al., 1997; Yela \& Holyoak, 1997; Beck et al., 2011a).

In contrast to the well established effects of environmental conditions and trap characteristics on the size and species composition of catches of nocturnal insects, surprisingly little is known about the distances at which moths respond to an artificial light source. However, this type of knowledge is essential for the correct interpretation of light-trap catches, for example in terms of the spatial scale and resolution of community-wide moth samples in biodiversity studies, or estimating the abundance of insects at a landscape scale from the numbers caught by light traps. There are only a few experimental studies on this topic specifically on moths. Bowden
(1982) supposes that the attraction radius of a $15 \mathrm{~W}$ mercury vapour lamp ranges from 50-250 m depending on the species. To evaluate the distance at which two temperate-zone noctuid moth species, Noctua pronuba and Agrotis exclamationis, respond to a light trap Baker \& Sadovy (1978) performed pioneering mark-releaserecapture (MRR) experiments and concluded the attraction range of a far stronger $125 \mathrm{~W}$ mercury vapour lamp is only about $3 \mathrm{~m}$. More recently, Beck \& Linsenmair (2006) used a similar approach to estimate the attraction radius of $125 \mathrm{~W}$ mercury vapour light sources for 18 species of hawk moth (Sphingidae) in tropical rainforest in Borneo. The distance from which these hawk moths returned to the light was usually below $30 \mathrm{~m}$. However, all these studies are based on a few selected species or one not very diverse family and are not on entire moth assemblages. In contrast, ecological research employing light-traps usually aims at analyses at the community level. As a result of the lack of community-wide experiments there is still uncertainty about the effective radius of attraction of light traps when used to study natural moth communities (Ricketts et al., 2001; Hawes et al., 2009) and usually the few results for single-species are generalized to the community level without supporting experimental evidence (Schmidt \& Roland, 2006). In the present study we report on two community-wide MRR experiments used to estimate the dependence on distance of the percentage of marked individuals of temperatezone moths recaptured at weak light sources. The hypotheses tested are:

(1) The effective radius of attraction of a light trap is small. 
Previous studies (Baker \& Sadovy, 1978; Beck \& Linsenmair, 2006) indicate that the range of attraction of light traps using $125 \mathrm{~W}$ mercury vapour bulbs is small. As we used a much weaker light source $(15 \mathrm{~W})$ the radius of attraction should be even smaller.

(2) Higher taxonomic groups (such as moth super-families) differ in their distance-dependent recapture rates.

Sensory and flight physiology are expected to show phylogenetic inertia, which should translate into taxon-specific responses. In particular, more robust flyers (such as many noctuids and arctiids) are expected to return from greater distances than smaller delicate moths (such as many geometrids or pyraloids).

(3) Moths with bigger wing spans return from greater distances than small moths.

Within moth families it is supposed that the larger moths return from greater distances as they are stronger fliers than the more delicate moths.

(4) Temperature affects recapture rates.

As ambient temperature affects moth catches positively, recapture rates should increase with increasing temperature.

\section{MATERIAL AND METHODS}

\section{Moth sampling and handling}

The first experiment in 2003 was carried out in the Botanical Garden of the University of Bayreuth (Germany). The study area $\left(49^{\circ} 55^{\prime} \mathrm{N}, 11^{\circ} 35^{\prime} \mathrm{E}, 355 \mathrm{~m}\right.$ a.s.l.) was located in a small, dense deciduous secondary forest with trees (mainly Betula pendula, Quercus robur, Acer pseudoplatanus, Fagus sylvatica and an admixture of a few Picea abies) ranging from 5 to $8 \mathrm{~m}$ in height. The light trap used for the experiments was placed on a small gravel road within this area, which provided a near-linear pathway for moths. Such corridors may facilitate moth flight (Mönkkönen \& Mutanen, 2003) and therefore increase the likelihood of recaptures. Moths were sampled for a total of 19 nights between 30 April and 30 May. Moth sampling started after dusk $(\sim 21: 00 \quad$ CEST). The light source was two battery-driven $15 \mathrm{~W}$ UV-light tubes (Sylvania, Blacklight-Blue, F15W/ BLB-T8; and Phillips, TLD, 15W/ 05) inside a white gauze "tower" (height $170 \mathrm{~cm}$, diameter $70 \mathrm{~cm}$ ). For practical reasons only moths with a wing span larger than $1.5 \mathrm{~cm}$ were used in the experiments. Moths that settled on the gauze were immediately placed individually in small plastic cups and transported to the laboratory. They were kept in the dark and cool $\left(5^{\circ} \mathrm{C}\right)$ over night to avoid damage. On the next day they were identified to species, anesthetized with $\mathrm{CO}_{2}$ and marked individually by drawing a number on the dorsal forewing (Edding, Paint marker 780 , silver) and then kept again at $5^{\circ} \mathrm{C}$ until released.

The marked moths were released during the next night at different distances from the light source at which they were caught. MRR experiments started at the beginning of dusk $(\sim 21: 00 \mathrm{~h}$ CEST) and ended three hours later or if the ambient temperature dropped below $10^{\circ} \mathrm{C}$. Release distances were 2, 3, 5, 7, 10, 12 , $15,18,20,25,30,35$ and $40 \mathrm{~m}$ in both directions along the small road on which the light trap was situated. For analyses of contingency tables releases at distances up to $20 \mathrm{~m}$ were later summed over $5 \mathrm{~m}$ intervals. Every specimen was first released 5 $\mathrm{m}$ from the light trap. Only individuals of species that were recaptured after being released $5 \mathrm{~m}$ from the light trap were subsequently tested at greater distances. Nightly ambient tempera- tures were recorded from the beginning until the end of each experiment using a minimum-maximum thermometer.

The second experiment was carried out in a floodplain forest in the Donau-Auen Nationalpark $\left(48^{\circ} 08^{\prime} \mathrm{N}, 16^{\circ} 41^{\prime} \mathrm{E}, 156 \mathrm{~m}\right.$ a.s.1.) near Orth (Austria) in 2007. The light trap was placed on a straight, narrow, east-west oriented forest road mainly surrounded by closed-canopy forest made up of Populus nigra, P. alba, Fraxinus excelsior, Acer campestre, Carpinus betulus and Q. robur. Again the light source consisted of two battery-driven $15 \mathrm{~W}$ UV-light tubes (Sylvania, Blacklight-Blue, F15W/ BLB-T8; Sylvania Blacklight F15W/ 350 BL-T8). Experiments took place on 4 to 5 June 2007 and 12 to 14 June 2007. All moths with a wing span $>1.5 \mathrm{~cm}$ were used in the MRR study. Unlike in the Bayreuth experiment moths were collected from the light trap, immediately anesthetized $\left(\mathrm{CO}_{2}\right.$ gas), marked (Edding, Paint marker 780) and then released at various distances from the light source. The moths were released over a greater range of distances than at Bayreuth $(5,10,15,20,30$, $40,50,60,70,80,90$ and $100 \mathrm{~m}$ ) again in both linear directions along the road on which the light trap was placed. Ambient temperature was recorded during the experiments $(\sim 22.00-1.30 \mathrm{~h})$ with a HOBO U12 data logger every $10 \mathrm{~min}$. In this experiment, the record for each moth released was temporally associated with the closest temperature record.

\section{Statistical analyses}

The times required by the moths to return to the light sources ranged from a few seconds up to three hours. We analyzed the data using three recapture intervals, i.e. 5, 10 and $20 \mathrm{~min}$ after release. There were no significant differences, with regard to the influence of distance, wing span and temperature on the percentage recaptured in these different time intervals. Therefore, we subsequently only counted those moths that returned within $5 \mathrm{~min}$ as "recaptures". The marked moths that arrived after 5 min were treated as "non-recaptures". We decided to use the 5 min time interval because (1) we considered this time span as sufficient for moths to warm up and fly up to $100 \mathrm{~m}$, but too short to avoid released moths coming across the light trap by chance after a random flight through the habitat and (2) Beck \& Linsenmair (2006) use this time interval in their MRR studies on Sphingidae, which means the results of these two studies can be compared.

Wing span data for every species was taken from literature (Palm, 1986; Skou, 1991; Hausmann, 2001, 2004; Mironov, 2003 ) and the geometric mean of minimum and maximum wing span was used as a proxy for body size in the subsequent analyses. Data from both experiments were analyzed separately as the details differed. Differences between taxa, release distances, wing span classes, sex (Bayreuth experiment) and release direction (Orth experiment) in terms of the probability of being recaptured were evaluated using $\mathrm{Chi}^{2}$ tests. The effects of release distance, ambient temperature and body size on the probability of recapture were assessed using multiple logistic regression. All analyses were calculated in Statistica 7.1 (StatSoft Inc.).

\section{RESULTS}

In the Bayreuth experiment 217 moths returned within $5 \mathrm{~min}$ and a further 108 moths returned within 6-80 min. In the Orth experiment 96 moths returned to the light source within $5 \mathrm{~min}$ and a further 264 returned within 6-212 min. If only those moths released at distances up to $40 \mathrm{~m}$ from the Orth light trap are considered then 89 moths returned within 5 min. 


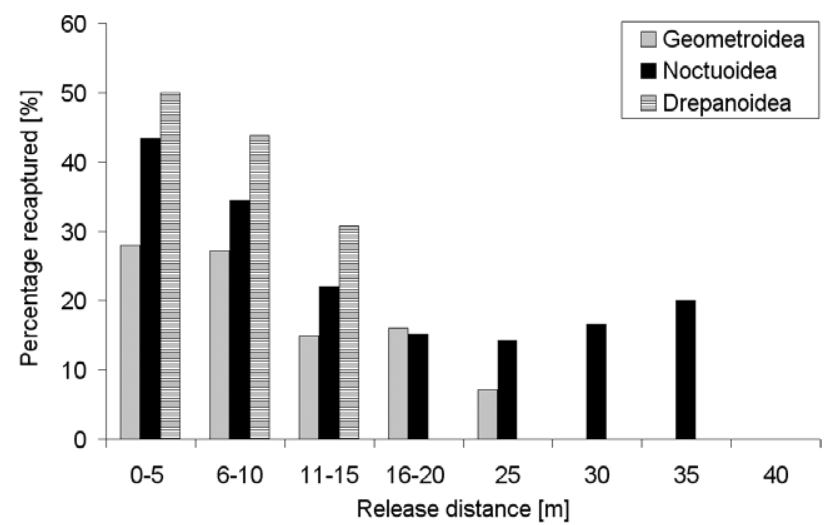

Fig. 1. Percentage of moths in three super-families recaptured in the Bayreuth experiment.

\section{Bayreuth experiment}

A total of 851 individuals belonging to 96 species of moth were caught and released in this experiment (Appendix). The number and percentage of moths recaptured was 217 and $25.5 \%$, respectively. The probability of recapture strongly decreased as the distance at which they were released increased. While there were 200 recaptures of 713 releases at distances up to $15 \mathrm{~m}$ (percentage recapture: $28.1 \%$ ) there were only 17 recaptures of the 138 moths released at distances from 16 to $40 \mathrm{~m}$ (percentage recapture: $12.3 \%$ ). This difference is highly significant $\left(\mathrm{Chi}^{2}{ }_{\mathrm{ldf}}=15.06, p<0.001\right)$.

The moths caught in this MRR experiment belonged to the superfamilies Noctuoidea, Geometroidea and Drepanoidea (Table 1). There was only a weak difference in the percentages of moths of the different super-families recaptured (Pearson's $\mathrm{Chi}^{2}{ }_{2 \mathrm{df}}=7.06, p=0.030$ ). Noctuoidea and Drepanoidea were recaptured more often than expected from marginal totals, while Geometroidea were recaptured less frequently than expected (Fig. 1).

For all moth super-families the probability of recapture strongly decreased with increase in the distance at which they were released from the light source (Table 2). This distance dependence was more marked for the Geometroidea than the Noctuoidea. The percentage recaptured significantly increased with increase in wing span in the Geometroidea (smallest species: Eupithecia tantillaria, $17.9 \mathrm{~mm}$; largest species: Hypomecis punctinalis, 44.3

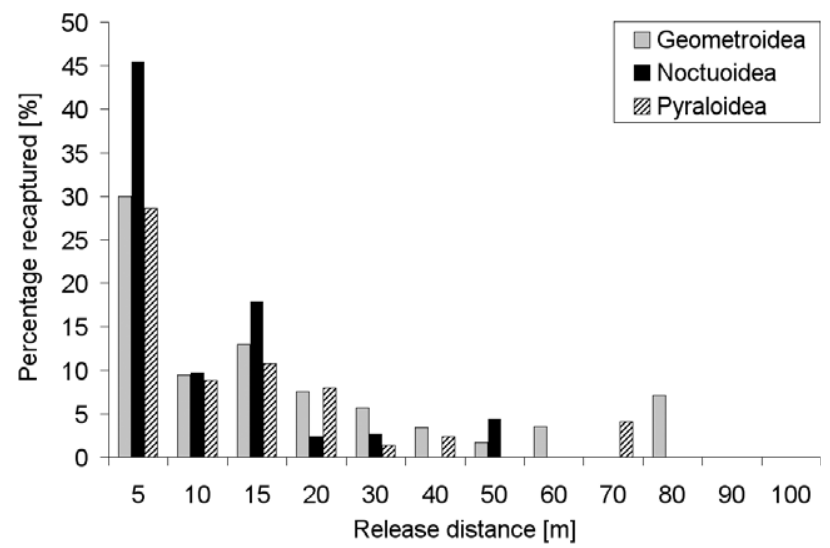

Fig. 2. Percentage of moths in three super-families recaptured in the Orth experiment.

$\mathrm{mm}$ ), but not in the Noctuoidea (smallest species: Clostera pigra, $23.8 \mathrm{~mm}$; largest species: Pheosia tremula, $53.4 \mathrm{~mm}$ ). Ambient mean temperature during each night of the experiment ranged from $10-20^{\circ} \mathrm{C}$ and did not significantly affect the percentage recaptured in any of the three moth taxa studied.

We caught fewer female than male moths (deviation from an equal sex ratio: $\mathrm{Chi}^{2}{ }_{1 \mathrm{df}}=14.745, p<0.0002$ ). However, the percentages recaptured did not differ between the sexes $\left(\mathrm{Chi}^{2}{ }_{1 \mathrm{df}}=0.04, p=0.838 ; 434\right.$ males released, 113 recaptured; 327 females released, 83 recaptured; for 90 individuals the sex was not recorded).

\section{Orth experiment}

We captured, marked and released 1,480 moths belonging to 104 species (Appendix). In this experiment 96 of the 1,480 moths released were recaptured within 5 min, which is equivalent to a percentage recaptured of only $6.5 \%$. Most of the moths belonged to the superfamily Geometroidea (776 individuals, 43 species), followed by Pyraloidea (427 individuals, 7 species) and Noctuoidea (251 individuals, 51 species) (Table 3). Most of the catch of Pyraloidea was made up of individuals of Pleuroptya ruralis (412 individuals).

In order to compare these results with those recorded in the Bayreuth experiment we also analyzed the data just for the release distances up to $40 \mathrm{~m}$. Of the 1,032 moths released up to $40 \mathrm{~m}$ from the light source only 89 or $8.6 \%$

TABLE 1. Numbers of individuals of three moth super-families and of the entire sample that were recaptured after being released at various distances from the light trap (Bayreuth experiment).

\begin{tabular}{|c|c|c|c|c|c|c|c|c|}
\hline \multirow{2}{*}{ Distance $[\mathrm{m}]$} & \multicolumn{2}{|c|}{ Noctuoidea } & \multicolumn{2}{|c|}{ Geometroidea } & \multicolumn{2}{|c|}{ Drepanoidea } & \multicolumn{2}{|c|}{ All moths } \\
\hline & Released & Recaptured & Released & Recaptured & Released & Recaptured & Released & Recaptured \\
\hline $0-5$ & 76 & 33 & 168 & 47 & 10 & 5 & 254 & 85 \\
\hline $6-10$ & 87 & 30 & 140 & 38 & 16 & 7 & 243 & 75 \\
\hline $11-15$ & 82 & 18 & 121 & 18 & 13 & 4 & 216 & 79 \\
\hline $16-20$ & 33 & 5 & 50 & 8 & 7 & 0 & 90 & 13 \\
\hline 25 & 7 & 1 & 14 & 1 & 1 & 0 & 22 & 2 \\
\hline 30 & 6 & 1 & 6 & 0 & 1 & 0 & 13 & 1 \\
\hline 35 & 5 & 1 & 4 & 0 & 0 & 0 & 9 & 1 \\
\hline 40 & 4 & 0 & 0 & 0 & 0 & 0 & 4 & 0 \\
\hline Total & 300 & 89 & 503 & 112 & 48 & 16 & 851 & 256 \\
\hline
\end{tabular}


TABLE 2. Results of multiple logistic regressions used to model the probability of recapture as a function of the distance at which moths were released, body size and ambient temperature. Distances at which they were released ranged from 2-40 m (Bayreuth experiment) and 5-100 m (Orth experiment). The results for the releases at distances up to $40 \mathrm{~m}$ in the Orth experiment were used for the comparison with the results of the Bayreuth experiment. Significant results (after false discovery rate correction: Waite \& Campbell, 2006) are highlighted in bold.

\begin{tabular}{|c|c|c|c|c|c|c|c|}
\hline & \multirow{2}{*}{$\mathrm{n}$} & \multicolumn{2}{|c|}{ Distance } & \multicolumn{2}{|c|}{ Wing span } & \multicolumn{2}{|c|}{ Temperature } \\
\hline & & $t$ & $p$ & $t$ & $p$ & $t$ & $p$ \\
\hline \multicolumn{8}{|l|}{ Bayreuth } \\
\hline Total & 847 & 5.675 & 0.001 & 3.975 & 0.001 & 0.203 & 0.839 \\
\hline Noctuoidea & 296 & 3.478 & 0.001 & 0.517 & 0.606 & 1.084 & 0.279 \\
\hline Geometroidea & 499 & 4.531 & 0.001 & 3.928 & 0.001 & 1.157 & 0.248 \\
\hline Drepanoidea & 44 & 2.133 & 0.039 & 1.116 & 0.271 & 0.540 & 0.592 \\
\hline \multicolumn{8}{|l|}{ Orth 5-100 m } \\
\hline Total & 1475 & 6.421 & 0.001 & 2.348 & 0.019 & 0.130 & 0.897 \\
\hline Noctuoidea & 247 & 3.138 & 0.002 & 1.670 & 0.091 & 0.711 & 0.478 \\
\hline Geometroidea & 771 & 4.399 & 0.001 & 2.339 & 0.020 & 0.623 & 0.534 \\
\hline Pyraloidea & 423 & 3.653 & 0.001 & 0.187 & 0.852 & 0.256 & 0.798 \\
\hline \multicolumn{8}{|l|}{ Orth 5-40 m } \\
\hline Total & 1028 & 5.959 & 0.001 & 2.649 & 0.008 & 0.724 & 0.469 \\
\hline Noctuoidea & 174 & 3.280 & 0.001 & 1.436 & 0.153 & 0.697 & 0.487 \\
\hline Geometroidea & 555 & 3.967 & 0.001 & 2.970 & 0.003 & 1.075 & 0.283 \\
\hline Pyraloidea & 272 & 3.278 & 0.001 & 0.201 & 0.841 & 0.272 & 0.786 \\
\hline
\end{tabular}

were recaptured. The percentages recaptured were significantly lower than at Bayreuth (Geometroidea: $\mathrm{Chi}^{2}{ }_{1 \mathrm{df}}=$ 32.98, Noctuoidea: $\mathrm{Chi}^{2}{ }_{\mathrm{dff}}=29.60$, both $p<0.0001$; Table 2).

Gross percentages recaptured did not significantly differ between the super-families Geometroidea, Noctuoidea and Pyraloidea $\left(\mathrm{Chi}^{2}{ }_{2 \mathrm{df}}=2.43, p=0.296\right.$; Fig. 2). Logistic regression analyses confirmed the highly significant negative effect of release distance on percentages recaptured for each of the major super-families (Table 2). Ambient temperature ranged from $16-22^{\circ} \mathrm{C}$ and did not affect the percentages recaptured (Orth [all data up to 100 $\left.\mathrm{m}]: \mathrm{t}_{1475}=0.13, p=0.870\right)$ and neither did the release direction relative to the light source $\left(\mathrm{Chi}^{2}{ }_{1 \mathrm{df}}=0.91, p=\right.$ 0.341). Like at Bayreuth wing span had a positive influence on the percentages of Geometroidea recaptured, which translated into a weak positive effect at the community level.

\section{DISCUSSION}

\section{Percentage recapture of moths}

In order to estimate the attraction radius of a weak artificial light source for moths we carried out two markrelease-recapture experiments. Overall the percentage recaptured was low ranging from $6.5 \%$ (Orth, release distances 5-100 m) to $25.5 \%$ (Bayreuth, 5-40 m). This difference was likely due to differences in the experimental design. At Bayreuth the moths were first released at a distance of $5 \mathrm{~m}$ from the light trap. Subsequently, only individuals of each species that were recaptured after first releasing them at a distance of $5 \mathrm{~m}$ were released at greater distances. This design was chosen to obtain at

TABLE 3. Numbers of individuals of three moth super-families and the entire sample released at various distances from the light trap that were recaptured in the Orth experiment.

\begin{tabular}{|c|c|c|c|c|c|c|c|c|}
\hline \multirow{2}{*}{ Distance $[\mathrm{m}]$} & \multicolumn{2}{|c|}{ Noctuoidea } & \multicolumn{2}{|c|}{ Geometroidea } & \multicolumn{2}{|c|}{ Pyraloidea } & \multicolumn{2}{|c|}{ All moths } \\
\hline & Released & Recaptured & Released & Recaptured & Released & Recaptured & Released & Recaptured \\
\hline 5 & 11 & 5 & 40 & 12 & 21 & 6 & 72 & 23 \\
\hline 10 & 31 & 3 & 74 & 7 & 34 & 3 & 139 & 13 \\
\hline 15 & 28 & 5 & 116 & 15 & 56 & 6 & 200 & 26 \\
\hline 20 & 42 & 1 & 119 & 9 & 50 & 4 & 211 & 14 \\
\hline 30 & 37 & 1 & 123 & 7 & 73 & 1 & 233 & 9 \\
\hline 40 & 29 & 0 & 87 & 3 & 42 & 1 & 158 & 4 \\
\hline 50 & 23 & 1 & 57 & 1 & 54 & 0 & 134 & 2 \\
\hline 60 & 12 & 0 & 57 & 2 & 28 & 0 & 97 & 2 \\
\hline 70 & 15 & 0 & 37 & 0 & 24 & 1 & 76 & 1 \\
\hline 80 & 5 & 0 & 28 & 2 & 14 & 0 & 47 & 2 \\
\hline 90 & 4 & 0 & 19 & 0 & 19 & 0 & 42 & 0 \\
\hline 100 & 14 & 0 & 18 & 0 & 12 & 0 & 44 & 0 \\
\hline Total & 251 & 16 & 775 & 58 & 427 & 22 & 1453 & 96 \\
\hline
\end{tabular}


least some recaptures since it was anticipated that the probability of recapture would be very low. At Orth the range of release distances was increased and individual moths were assigned to be released at great distances irrespective of earlier success in recapturing representatives of the same species. This procedure resulted in low percentages of recapture.

MRR studies on moths tend to yield low percentages of recapture (Nieminen, 1996; Keil et al., 2001; Merckx et al., 2009, 2010), which are in accordance with our results. The reasons for low percentages of recapture are poorly known. Low percentages of recapture recorded in studies of the dispersal by moths may result from transporting them from the field to the laboratory and back again. These sudden changes in environmental conditions might trigger unnatural dispersal behaviour (Qureshi et al., 2005). However, in our study the percentages recaptured were higher in the Bayreuth experiment, which included transportation of the moths to the laboratory and back, than in the Orth experiment in which moths were not brought back to the laboratory. All MRR experiments suffer from behavioural biases as the catchability of the moths may be influenced by the behavioural context of movements (Van Dyck \& Baguette, 2005), landscape patterns (Merckx et al., 2010), handling effects (Mallet et al., 1987) and other potential sources of error. The important point relevant to our study is that even when we increased the percentage recaptured by increasing the time intervals within which returning moths were counted as "recaptures" (we also analysed return time thresholds of 10 and $20 \mathrm{~min}$; data not shown) this did not lead to any statistically significant changes in the results. We therefore accepted the shortest time threshold as the most representative one for measuring the spontaneous movement patterns of moths immediately after release.

\section{Factors influencing percentage recaptured}

For all super-families of moths in both experiments the percentage recaptured strongly decreased with increase in the distance at which they were released. This was expected since the visual stimulus provided by an artificial light source decreases exponentially with distance. Contrary to our expectation that the higher taxonomic groups would differ in their distance-dependent percentages recaptured there were no obvious differences in the shape of this distance dependency among the major super-families included in our study, viz. Noctuoidea, Geometroidea, Drepanoidea and Pyraloidea. If responsive to a light trap, then representatives of all these superfamilies of moths were similarly attracted to the light as there were no significant biases in their distance dependent responses to the light traps. Percentage of Geometroidea recaptured increased with body size in both experiments, but the strength of this effect was much weaker than that of the distance at which they were released. We expected a body size effect as there are positive relationships between body size and dispersal range for various moth species (Nieminen, 1996; Dulieu et al., 2007). Our results might indicate that body size is more important in moth families with a more delicate mor- phology such as geometrids. To further explore the importance of moth body size in determining the composition of light trap catches one should systematically check a wider range of species of noctuid or pyraloid moths of different sizes.

Although temperature affects the size of light trap catches of moths (Butler et al., 1999; Beck et al., 2011a) and we expected such an effect on the percentages recaptured, ambient temperature did not affect the percentages recaptured in our experiments. The reason for this might be that both experiments took place under rather favourable environmental conditions. No experiments were carried out when temperature dropped below $10^{\circ} \mathrm{C}$. Therefore, the species pool for this study was limited to those moths that fly spontaneously under these conditions, which also includes abiotic factors like cloud cover and phase of the moon that might also influence moth catches.

Light traps usually catch fewer females than males as occurred in our study. Beck \& Linsenmair (2006) propose that this could be due to differences in the activity of the sexes as well as differences in their attraction to light. Such a behavioural bias was recently confirmed experimentally by Altermatt et al. (2009). In our study there were no discrepancies in the percentages of males and females recaptured suggesting that once individuals of a moth species react to a light source their attraction radius is similar irrespective of their sex. However, our results do not rule out that in certain species such sex-related differences might occur.

\section{Attraction radius of light traps}

Our community-wide experiments show that percentage of moths recaptured decreases with increase in the distance at which they are released. Very few recaptures occurred at release distances beyond $40 \mathrm{~m}$. We anticipated the attraction radius of a light trap would be short, because previous studies report attraction only over short distances and we used an even weaker light source. The predicted percentage recapture based on logistic regression of the results for the moths included in our experiments that were released at a distance of $3 \mathrm{~m}$ (the attraction range claimed by Baker \& Sadovy (1978) for Noctua pronuba and Agrotis exclamationis) only ranged from $19 \%$ to $39 \%$. Hence, even at this short distance the majority of the moths that were released did not fly to the light trap. The findings of this multi-species comparison accord with those of other studies based on fewer species. Beck \& Linsenmair (2006) report a mean attraction radius for Sphingidae in Borneo to a more intense $125 \mathrm{~W}$ MVlamp in their MRR experiments of below $30 \mathrm{~m}$. So even for large, robust moths that are known to be excellent and very fast flyers like hawk moths the attraction radius of a light source much brighter than the one we used in our experiments, is surprisingly low. Qureshi et al. (2005) found no difference in the numbers of male European corn borers caught by $15 \mathrm{~W}$ black light traps and pheromone traps, which were placed only $2 \mathrm{~m}$ apart from each other, suggesting that there was no interference between these traps even at this small spatial scale. Various studies (Beck et al., 2002; Schulze \& Fiedler, 2003) indicate 
clear differences in the samples of insects caught by light traps located in different forest strata (20-40 m height). All the more recent data support the earlier results of Baker \& Sadovy (1978) but not the estimates of Bowden (1982).

A reason for these different views could be that there is a conceptual misunderstanding of the sampling range and the distance from which insects respond to light traps. Shelly \& Edu (2010) define sampling range as the maximum distance from which an insect can physically reach a trap in a given time interval, whereas attraction range is the maximum distance from which an insect shows directed movement towards the attractant. Accordingly, the (potential) sampling range is always larger than the (real) attraction range, since the sampling range encompasses any area that the insect has crossed by spontaneous movements before entering the attraction radius. The low percentage of moths recaptured and the short distances from which moths returned to a weak light source in our experiments support the notion that the attraction radius of weak light traps for moths is much lower than their sampling range.

As mentioned above all the results from well-controlled studies concur that the effective attraction radius of an artificial light source for moths is rather low, mostly $<30$ $\mathrm{m}$ and often $<10 \mathrm{~m}$. In addition, as the earlier studies were only on single species or small taxon assemblages novel empirical data was needed in order to assess if the generalizations based on these results can be applied to larger communities. Our experiments using a broad range of central European moth species confirm that short attraction distances are not only a trait of single species, but can safely be extrapolated to larger assemblages.

What do these findings imply for moth biodiversity studies?

Moths are increasingly being used as indicators of habitat quality or biodiversity (Kitching et al., 2000; Summerville et al., 2004; Beck et al., 2011b). Species richness and assemblage composition are surveyed in a standardized manner in order to compare different sites or monitor changes over time. Serving as surrogates for more inclusive fractions of biodiversity, moth inventory data can be related to various environmental parameters. For example, moth community studies have addressed aspects such as effects of logging, habitat conversion and the effects of succession or fragmentation on insect biodiversity (Intachat et al., 1999; Fiedler \& Schulze, 2004; New, 2004; Schmidt \& Roland, 2006; Fiedler et al., 2007; Maleque et al., 2009). All these inventories rely exclusively on samples collected by light traps. Therefore spatial resolution of such samples is critical in interpreting the data and providing insights into ecological patterns and processes.

In many of the aforementioned studies light trap samples of moths revealed a high spatial resolution at the range of some dozens of meters and below, despite the potentially large mobility of flying moths. Our data from two community-wide MRR experiments together with that from other recent studies (Wirooks, 2005; Beck \&
Linsenmair, 2006) now confirm that the attraction of moths to light traps largely occurs at very small spatial scales, often even below $10 \mathrm{~m}$. In the Bayreuth experiment only $32 \%$ and in the Orth experiment just $17 \%$ of the moths released at distances up to $10 \mathrm{~m}$ were recaptured. Therefore, our results corroborate the perception that weak artificial light sources are an excellent way to accurately characterize and monitor moth communities in a selected habitat, since the low attraction radius means that few species from adjacent habitats are likely to be caught by such traps.

ACKNOWLEDGEMENTS. We thank F. Bodner for help with the statistical analyses. J. Beck, F. Bodner, C.H. Schulze and two anonymous reviewers gave constructive comments on the manuscript. The University of Bayreuth (especially the director of the Botanical Garden, G. Aas) and the authorities of the National Park Donau-Auen (in particular C. Baumgartner) kindly permitted us to carry out field work at these sites. A number of enthusiastic students and C.H. Schulze helped with the field work.

\section{REFERENCES}

Altermatt F., Baumeyer A. \& Ebert D. 2009: Experimental evidence for male biased flight-to-light behavior in two moth species. Entomol. Exp. Appl. 130: 259-265.

AXMACHER J.C. \& FiedLeR K. 2004: Manual versus automatic moth sampling at equal light sources - a comparison of catches from Mt. Kilimanjaro. J. Lepid. Soc. 58: 196-202.

BAKER R.R. \& SADOVY Y. 1978: The distance and nature of the light trap response of moths. Nature 276: 818-821.

BECK J. \& CHEY V.K. 2007: Beta-diversity of geometrid moths from northern Borneo: effects of habitat, time and space. $J$. Anim. Ecol. 76: 230-237.

BECK J. \& LinSENMAIR K.E. 2006: Feasibility of light-trapping in community research on moths: Attraction radius of light, completeness of samples, nightly flight times and seasonality of Southeast-Asian hawkmoths (Lepidoptera: Sphingidae). J. Res. Lepid. 39: 18-36.

Beck J., Schulze C.H., Linsenmair K.E. \& Fiedler K. 2002: From forest to farmland: diversity of geometrid moths along two habitat gradients on Borneo. J. Trop. Ecol. 18: 33-51.

BecK J., Brehm G. \& Fiedler K. 2011a: Links between the environment, abundance and diversity of Andean moths. Biotropica 43: 208-217.

Beck J., Schwanghart W., Chey V.K. \& Holloway J.D. 2011b: Predicting geometrid moth diversity in the Heart of Borneo. Insect Conserv. Diver. 4: 173-183.

Bowden J. 1982: An analysis of factors affecting catches of insects in light traps. Bull. Entomol. Res. 72: 535-556.

Butler L., Kondo V., Barrows, E.M. \& Townsend E. C. 1999: Effects of weather conditions and trap types on sampling for richness and abundance of forest Macrolepidoptera. Environ. Entomol. 28: 795-811.

Dulieu R.L., Merckx T., Paling N. \& Holloway G. 2007: Using mark-release-recapture to investigate habitat use in a range of common macro-moth species. Centre for Wildlife Assessment \& Conservation E-Journal 1: 1-9. Complete URL (http://www.reading.ac.uk/cwac/CWAC\%202008/e-journal.ht $\mathrm{m})$.

FAYle T.M., Sharp R.E. \& Majerus M.E.N. 2007: The effect of moth trap type on catch size and composition in British Lepidoptera. Br. J. Nat. Hist. 20: 221-232. 
Fiedler K. \& Schulze C.H. 2004: Forest modification affects diversity (but not dynamics) of speciose tropical pyraloid moth communities. Biotropica 36: 615-627.

Fiedler K., Hilt N., Brehm G. \& Schulze C.H. 2007: Moths at tropical forest margins - how mega-diverse insect assemblages respond to forest disturbance and recovery In Tscharntke T., Leuschner C., Zeller M., Guhardja E. \& Bidin A. (eds.): The Stability of Tropical Rainforest Margins: Linking Ecological, Economic and Social Constraints of Land Use and Conservation. Springer, Berlin, pp. 39-60.

Hausmann A. 2001:The geometrid moths of Europe, Vol. 1. Apollo Books, Stenstrup, Denmark, 282 pp.

Hausmann A. 2004: The geometrid moths of Europe, Vol. 2. Apollo Books, Stenstrup, Denmark, 600 pp.

Hawes J., da Silva Motta C., Overal W.L., Barlow J., Gardner T.A. \& Peres C.A. 2009: Diversity and composition of Amazonian moths in primary, secondary and plantation forests. J. Trop. Ecol. 25: 281-300.

HOLYOAK M., JAROSIK V. \& NovÁK I. 1997: Weather-induced changes in moth activity bias measurement of long-term population dynamics from light trap samples. Entomol. Exp. Appl. 83: 329-335.

Intachat J., Holloway J.D. \& Speight M.R. 1999: The impact of logging on geometrid moth populations and their diversity in lowland forests of Peninsular Malaysia. J. Trop. For. Sci. 11: $61-78$.

KeIL S., Gu H. \& Dorn S. 2001: Response of Cydia pomonella to selection on mobility: Laboratory evaluation and field verification. Ecol. Entomol. 26: 495-501.

Kitching R.L., OrR A.G., Thalib L., Mitchell H., Hopkins M.S. \& Graham A.W. 2000: Moth assemblages as indicators of environmental quality in remnants of upland Australian rain forest. J. Appl. Ecol. 37: 284-297.

Leinonen R., Söderman G., Itämies J., Rytkönen S. \& Rutanen I. 1998: Intercalibration of different light-traps and bulbs used in moth monitoring in northern Europe. Entomol. Fenn. 9: $37-51$.

Maleque M.A., Maeto K. \& Ishi H.T. 2009: Arthropods as bioindicators of sustainable forest management, with a focus on plantation forests. Appl. Entomol. Zool. 44: 1-11.

Mallet J., Longino J.T., Murawski D., Murawski A. \& GamboA A.S.D. 1987: Handling effects in Heliconius: Where do all the butterflies go? J. Anim. Ecol. 56: 377-386.

Merckx T., Feber R.E., Dulieu R.L., Townsend M.C., Parsons M.S., Bourn N.A.D., Riordan P. \& MacDonald D.W. 2009: Effect of field margins on moths depends on species mobility: Field-based evidence for landscape-scale conservation. Agric. Ecosyst. Environ. 129: 302-309.

Merckx T., Feber R., Parsons M., Bourn N., Townsend M., RioRDAN P. \& MACDONALD D. 2010: Habitat preference and mobility of Polia bombycina: are non-tailored agrienvironment schemes any good for a rare and localised species? J. Insect Conserv. 14: 499-510.

Mironov V. 2003: Larentiinae II (Perizomini and Eupitheciini). In Hausmann A. (ed.): The Geometrid Moths of Europe, Vol. 4. Apollo Books, Stenstrup, 463 pp.

MÖNKKÖNEN M. \& MUtANEN M. 2003: Occurrence of moths in boreal forest corridors. Conserv. Biol. 17: 468-475.

NEw T.R. 2004: Moths (Insecta: Lepidoptera) and conservation: background and perspective. J. Insect Conserv. 8: 79-94.
NiEminen M. 1996: Migration of moth species in a network of small islands. Oecologia 108: 643-651.

Palm E. 1986: Nordeuropas Pyralider - med scerligt henblik på den danske fauna (Lepidoptera: Pyralidae). [Handbook on the Pyralid Moths of North Europe.] Fauna Bøger, Svendborg, $287 \mathrm{pp}$.

Qureshi J.A., Buschman L.L., Throne J.E. \& Ramaswamy S.B. 2005: Adult dispersal of Ostrinia nubilalis Hubner (Lepidoptera: Crambidae) and its implications for resistance management in Bt-maize. J. Appl. Entomol. 129: 281-292.

Ricketts T.H., Daily G.C., Ehrlich P.R. \& Fay J.P. 2001: Countryside biogeography of moths in a fragmented landscape: Biodiversity in native and agricultural habitats. Conserv. Biol. 15: 378-388.

Schmidt B.C. \& Roland J. 2006: Moth diversity in a fragmented habitat: Importance of functional groups and landscape scale in the boreal forest. Ann. Entomol. Soc. Am. 99: 1110-1120.

Schulze C.H. \& Fiedler K. 2003: Vertical and temporal diversity of a species-rich moth taxon in Borneo. In Basset Y., Novotny V., Miller S. \& Kitching R. (eds.): Arthropods of Tropical Forests: Spatio-Temporal Dynamics and Resource Use in the Canopy. Cambridge Univ. Press, Cambridge, pp. 69-85.

Shelly T.E. \& Edu J. 2010: Mark-release-recapture of males of Bactrocera cucurbitae and B. dorsalis (Diptera: Tephritidae) in two residential areas of Honolulu. J. Asia-Pac. Entomol. 13: 131-137.

Skou P. 1991: Nordens ugler: Handbog over de i Danmark, Norge, Sverige, Finland og Island forekommende arter af Herminiidae og Noctuidae (Lepidoptera). [Nordic Owlet Moths: Handbook of the Noctuidae and Herminiidae of Denmark, Norway, Sweden, Finland and Iceland.] Apollo Books, Stenstrup, $565 \mathrm{pp}$.

Summerville K.S. \& CRist T.O. 2005: Temporal patterns of species accumulation in a survey of Lepidoptera in a beechmaple forest. Biodivers. Conserv. 14: 3393-3406.

Summerville K.S., RitTer L.M. \& Crist T.O. 2004: Forest moth taxa as indicators of lepidopteran richness and habitat disturbance: a preliminary assessment. Biol. Conserv. 116: 9-18.

Thomas A.W. \& Thomas G.M. 1994: Sampling strategies for estimating moth species diversity using a light trap in a northeastern softwood forest. J. Lepid. Soc. 48: 85-105.

VAN DyCK H. \& BAGUETTE M. 2005: Dispersal behaviour in fragmented landscapes: Routine or special movements? Basic Appl. Ecol. 6: 535-545.

Waite T.A. \& CAmpbell L.G. 2006: Controlling the false discovery rate and increasing statistical power in ecological studies. Ecoscience 13: 439-442.

WIROOKs L. 2005: Die ökologische Aussagekraft des Lichtfangs: Eine Studie zur Habitatanbindung und kleinräumigen Verteilung von Nachtfaltern und ihren Raupen. Wolf \& Kreuels, Havixbeck-Hohenholte, 302 pp.

Yela J.L. \& HolyoAK M. 1997: Effects of moonlight and meteorological factors on light and bait trap catches of noctuid moths (Lepidoptera: Noctuidae). Environ. Entomol. 26: 1283-1290.

Young M. 2005: Insects in flight. In Leather S. (ed.): Insect Sampling in Forest Ecosystems. Blackwell, Malden, pp. 116-145.

Received August 12, 2011; revised and accepted September 30, 2011 
APPENDIX. Species of moths (in alphabetical order within super-families) recorded in the two MRR experiments on the responses of moths to low-power light traps. Nomenclature follows Fauna Europaea (URL: http://www.faunaeur.org/). Species that were recaptured are printed in bold.

\begin{tabular}{|c|c|c|c|c|c|c|c|c|}
\hline Species & Orth & Bayreuth & Species & Orth & Bayreuth & Species & Orth & Bayreuth \\
\hline DREPANOIDEA & & & Lycia hirtaria & & $\bullet$ & Harpyia milhauseri & & $\bullet$ \\
\hline Drepana falcataria & & 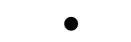 & Macaria alternaria & & & Herminia grisealis & $\bullet$ & \\
\hline Ochropacha duplaris & & $\bullet$ & Macaria liturata & $\bullet$ & $\bullet$ & Herminia tarsicrinalis & $\bullet$ & \\
\hline Tethea or & $\bullet$ & $\bullet$ & Macaria notata & & $\bullet$ & Hoplodrina ambigua & $\bullet$ & \\
\hline Thyatira batis & $\bullet$ & $\bullet$ & Melanthia procellata & $\bullet$ & & Hoplodrina blanda & $\bullet$ & \\
\hline Watsonalla binaria & & $\bullet$ & Odontopera bidentata & & & Hypena proboscidalis & $\bullet$ & $\bullet$ \\
\hline GEOMETROIDEA & & & Opisthograptis luteolata & & $\bullet$ & Lacanobia contigua & $\bullet$ & \\
\hline Abraxas sylvata & $\bullet$ & $\bullet$ & Ourapteryx sambucaria & $\bullet$ & & Lacanobia oleracea & $\bullet$ & \\
\hline Acasis viretata & & & Paradarisa consonaria & $\bullet$ & & Lacanobia thalassina & $\bullet$ & \\
\hline Aethalura punctulata & & & Parectropis similaria & $\bullet$ & & Leucania obsoleta & $\bullet$ & \\
\hline Alcis repandata & $\bullet$ & & Pasiphila rectangulata & $\bullet$ & & Lithophane socia & & $\bullet$ \\
\hline Angerona prunaria & $\bullet$ & & Peribatodes rhomboidarius & $\bullet$ & & Mamestra brassicae & & $\bullet$ \\
\hline Anticlea derivata & & & Philereme transversata & $\bullet$ & & Mesapamea secalis & $\bullet$ & \\
\hline Aplocera plagiata & & ? & Plagodis dolabraria & & $\bullet$ & Mythimna albipuncta & & $\bullet$ \\
\hline Ascotis selenaria & $\bullet$ & & Plemyria rubiginata & $\bullet$ & & Mythimna comma & & $\bullet$ \\
\hline Biston betularius & $\bullet$ & & Scopula immorata & $\bullet$ & & Mythimna l-album & $\bullet$ & \\
\hline Cabera exanthemata & $\bullet$ & $\bullet$ & Selenia dentaria & & & Mythimna turca & $\bullet$ & \\
\hline Cabera pusaria & $\bullet$ & & Selenia tetralunaria & $\bullet$ & $\bullet$ & Noctua pronuba & • & \\
\hline Campaea margaritata & $\bullet$ & & Spargania luctuata & & & Notodonta ziczac & & $\bullet$ \\
\hline Cepphis advenaria & & & obeliscata & & & Ochropleura plecta & $\bullet$ & $\bullet$ \\
\hline Chiasmia clathrata & $\bullet$ & & Timandra comae & - & & Odontosia carmelita & & $\bullet$ \\
\hline Chloroclysta siterata & & & Trichopteryx carpinata & & & strigilis & - & \\
\hline Cleora cinctaria & $\bullet$ & & Xanthorhoe designata & - & $\bullet$ & Orthosia cerasi & & $\bullet$ \\
\hline Cosmorhoe ocellata & & & Xanthorhoe ferrugata & & & Orthosia gothica & & $\bullet$ \\
\hline Cyclophora albipunctata & & & Xanthorhoe fluctuata & & & a gracilis & & $\bullet$ \\
\hline phora annularia & $\bullet$ & & Xanthorhoe spadicearia & $\bullet$ & $\bullet$ & Orthosia incerta & & $\bullet$ \\
\hline phora punctaria & $\bullet$ & & NOCTUOIDEA & & & Orthosia opima & & $\bullet$ \\
\hline oma truncata & & & Abrostola triplasia & - & $\bullet$ & Panolis flammea & & $\bullet$ \\
\hline Earophila badiata & & & Acronicta rumicis & & & Paracolax tristalis & $\bullet$ & \\
\hline Ecliptopera silaceata & $\bullet$ & & Actinotia polyodon & & & Pelosia muscerda & $\bullet$ & \\
\hline Ectropis crepuscularia & $\bullet$ & & Agrotis exclamationis & - & & Phalera bucephala & $\bullet$ & \\
\hline Epione repandaria & $\bullet$ & & Anaplectoides & & & a tremula & $\bullet$ & $\bullet$ \\
\hline Epirrhoe alternata & $\bullet$ & - & Apamea crenata & - & & natobia fuligir & $\bullet$ & \\
\hline nebulata & $\bullet$ & & onoglypha & $\bullet$ & & Polypogon tentacularia & $\bullet$ & \\
\hline Eulithis mellinata & $\bullet$ & & Arctornis l-nigrum & $\bullet$ & & Pterostoma palpina & $\bullet$ & $\bullet$ \\
\hline Euphyia unangulata & & & Atypha pulmonaris & $\bullet$ & & Ptilodon capucina & & $\bullet$ \\
\hline Eupithecia subfuscata & & & Axylia putris & $\bullet$ & & Ptilodon cucullina & $\bullet$ & $\bullet$ \\
\hline Eupithecia tantillaria & & & Callimorpha dominula & $\bullet$ & & Scoliopteryx libatrix & $\bullet$ & \\
\hline Gandaritis pyraliata & $\bullet$ & & Calliteara pudibunda & & & Spatalia argentina & $\bullet$ & \\
\hline Hemistola chrysoprasaria & $\bullet$ & & Cerastis rubricosa & & $\bullet$ & Spilosoma lubricipeda & $\bullet$ & $\bullet$ \\
\hline Hemithea aestivaria & $\bullet$ & & minea & $\bullet$ & & Spilosoma lutea & $\bullet$ & \\
\hline rticata & $\bullet$ & & a trigran & & $\bullet$ & us fagi & $\bullet$ & \\
\hline rsata & $\bullet$ & & curtula & $\bullet$ & $\bullet$ & Subacronicta megacephala & & $\bullet$ \\
\hline Horisme vitalbata & $\bullet$ & & Clostera pigra & & $\bullet$ & Tyta luctuosa & - & \\
\hline Hydria cervinalis & & & Colocasia coryli & & & Xestia c-nigrum & $\bullet$ & $\bullet$ \\
\hline Hydria undulata & & & Conistra vaccinii & & & Xestia ditrapezium & $\bullet$ & \\
\hline Hydriomena impluviata & & & Cucullia umbratica & $\bullet$ & & Xestia stigmatica & $\bullet$ & \\
\hline Hylaea fasciaria & & & Deltote pygarga & & & PYRALOIDEA & & \\
\hline Hypomecis punctinalis & $\bullet$ & & Diachrysia chrysitis & $\bullet$ & $\bullet$ & Anania hortulata & $\bullet$ & \\
\hline Hypomecis roboraria & $\bullet$ & & Diarsia florida & & $\bullet$ & Aphomia sociella & - & \\
\hline Idaea aversata & $\bullet$ & & Drymonia dodonaea & - & & Hypsopygia glaucinalis & - & \\
\hline Lampropteryx suffumata & & & nonia ruficornis & & - & Ostrinia nubilalis & $\bullet$ & \\
\hline Ligdia adustata & $\bullet$ & $\bullet$ & Euplexia lucipara & $\bullet$ & $\bullet$ & Pleuroptya ruralis & $\bullet$ & \\
\hline Lithosia quadra & $\bullet$ & & Euproctis similis & $\bullet$ & & Sclerocona acutella & $\bullet$ & \\
\hline Lobophora halterata & & & Euxoa obelisca & $\bullet$ & & SPHINGOIDEA & & \\
\hline Lomaspilis marginata & 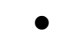 & & Furcula furcula & & & Laothoe populi & 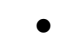 & \\
\hline Lomographa bimaculata & & - & Gluphisia crenata & - & & Mimas tiliae & $\bullet$ & \\
\hline Lomographa temerata & - & $\bullet$ & & & & & & \\
\hline
\end{tabular}

